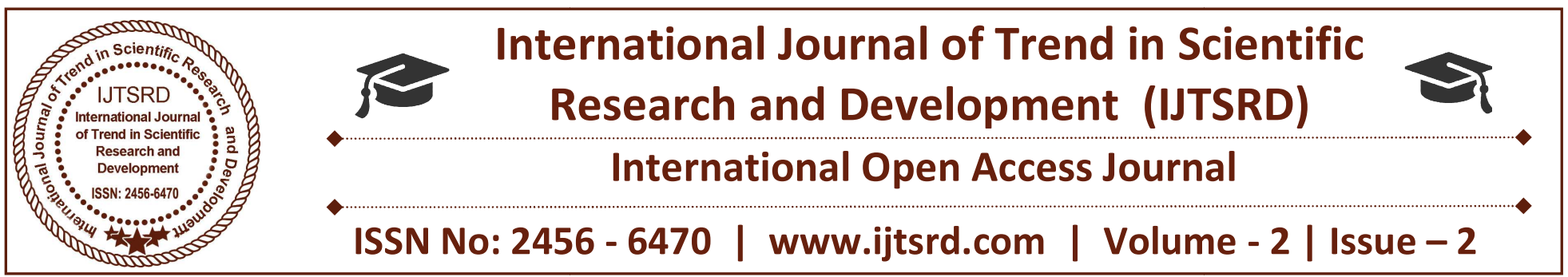

\title{
Effective Badminton Coaching Schema using PIC16F887 Microcontroller
}

G. Naveen Balaji

Assistant Professor, Department of ECE, SNS College of Technology, Coimbatore, India

\author{
N. V. Hari Suriya \\ UG Student, Department of ECE, \\ SNS College of Technology, Coimbatore, India
}

\section{ABSTRACT}

This project shows that the badminton player can practice without the help of coach. By using 16F887 pic microcontroller, some led and buzzer. This helps the player to practice by using the coach-less method which is made by pic microcontroller. This also helps the coach to concentrate on other players too.

Keywords: PIC, Microcontroller, Badminton, LED, embedded $C$

\section{Introduction}

Badminton is a sport played using racquets to hit a shuttlecock across a net. It may be played by large number of teams, the most common form of game are Singes (with one player each side) and doubles (with two players each side). It is often played as a casual outdoor game as well as indoor court. The points are scored by striking the shuttlecock with the racquet and landing it within the opposing side's half of the court. For training the player coach as to play a major role. By that way the coach has to give commend to the player each and every time for the movement of player and to monitor the player weather he is doing his training in a correct manner. By doing this coach do not have more time to monitor all the players for this purpose we are introducing a project that was a coach-less training kit the main concept was player can practice without the help of coach by the indication of light and busser placed in each and every corner of the court.

\section{Badminton Court}

The badminton court was made up of hardwood floors or synthetic rubber mats made specifically for badminton players. The court is divided into two halves for two separate teams. The standard court contains lines for both singles and doubles there are several lines like base line, centre line, short service line, double side line and double long service line.

\section{Law of BWF}

- The length of the court is $13.4 \mathrm{~m}$.the net is placed at the centre and divides the court inti two equal parts.

- The width of the court will depends on whether the game is singles or doubles. For singles the width is $5.2 \mathrm{~m}$ and for doubles width is $6.1 \mathrm{~m}$.

Doubles long service line is $76 \mathrm{~cm}$ away from the baseline at each end of the court.

- Distance of short service line to the net is 1.9 wherein the centre line is $3.88 \mathrm{~m}$ from the baseline.

\section{TRAINING METHOD}

\section{A. Coaching method}

The existing coaching method of badminton game is that player has to obey the commend of coach to do 
the correct practice by this existing method the coach will give the comment that player has to go front left, front right, left, right, back left, back right by doing this method coach can take care only to the current player who has been practicing and cant able to concentrate on other players.

\section{B. Coach-less method}

The main advantage of coach-less method is to concentrate on all players who $r$ practicing. The proposed method is by using pic microcontroller of 16 f887 can be programed by the wish of coach and it can indicate by using led lights and bussers the microcontroller will be programmed and the voltage will be given to led with has been located by the front of the player front left, front right, left, right. The 2 buzzer has been placed back of the player because player can't be able to see the back side with led's. The proposed method has been implemented and picture has been attached for the reference.

\section{PIC16F887}

A microcontroller is a compact microcomputer designed for the operation of embedded system. The microcontroller of pic16f887 is one of the most common integrated circuit which Is used in automation for many general purpose and a typical microcontroller include a processor, peripherals and memory. The most feature of PIC16F887 is easy to handle and it has 40 different pins and has five different PORT namely PORTA, PORTB, PORTC, PORTD, PORTE.

The PORTA, PORTB, PORTC, PORTD has 8 pins each and PORTE has 4 pins and 2 set of VCC and VDD. The clock frequency of PIC16F887 is $0-20 \mathrm{mhz}$. the operating voltage is $2.5-5 \mathrm{v}$. It also has a most modern microcontroller of $16 \mathrm{f} 887 \mathrm{a}$ with same operation. Both IC has an internal clock frequency the Nano watt could be useful for battery operation. It has 2 ports of analogue pins which can take analogue signal has input and can convert it to digital signal and a watch dog timer.

The advantage of PIC16F887 microcontroller is low cost and EEPROM (electrically erasable programmable read-only memory) it can erase a program and can reprogram into the microcontroller.

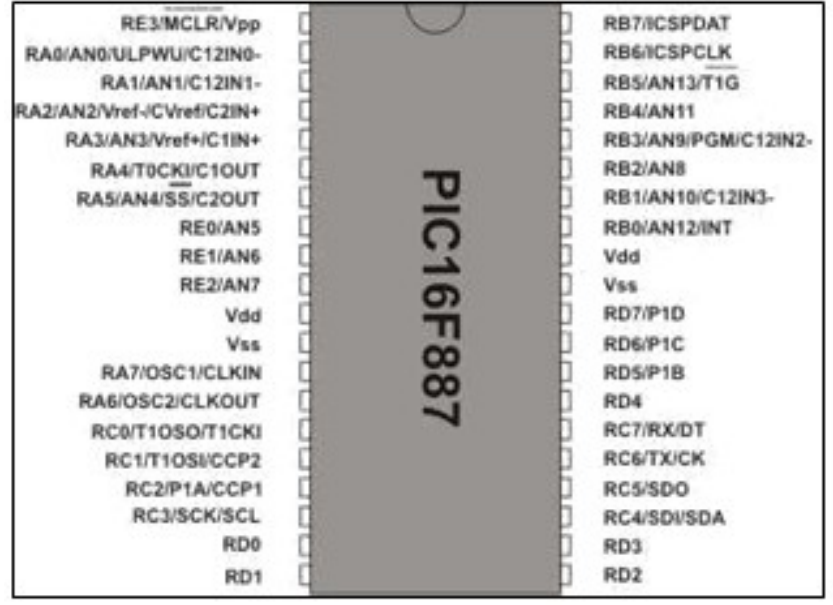

Fig.1 Pin diagram of PIC16F887

\section{Block diagram}

Block diagram represents that the control unit has pic $16 f 887$ microcontroller and logical unit which contains switches to control in period of times that has been programed the control unit is given to the led driver board. And the connection is going to the court

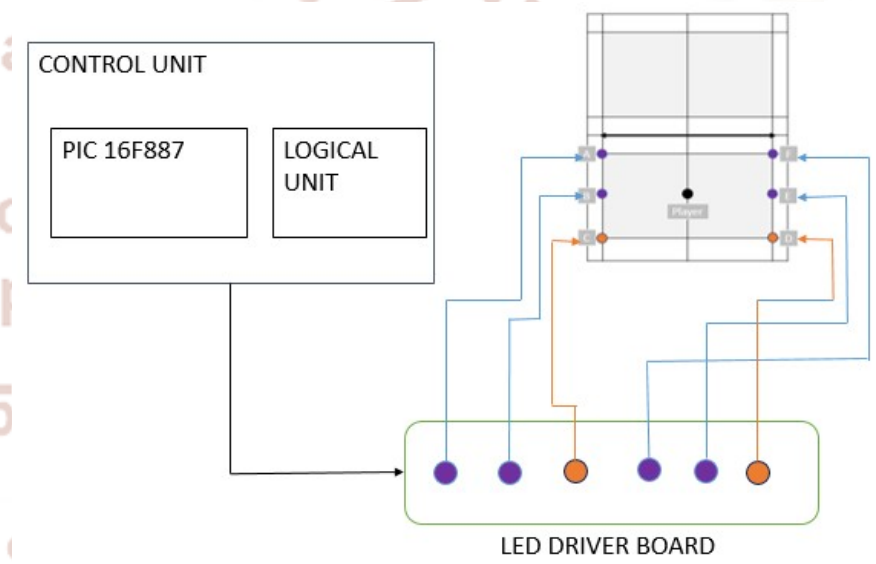

Fig.2 Block diagram of coach-less schema

VII. FLOW CHART AND ALGORITHM

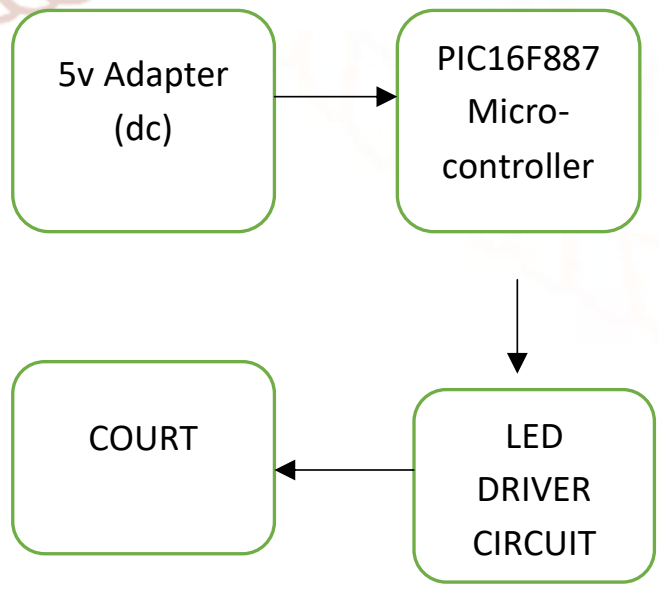

Fig.3 Flow chart of coach-less schema 
The flow chart explains that the $5 \mathrm{v}$ adapter is converted into $230 \mathrm{v}$ ac supply and power is given to the pic 168887 microcontroller and is given to the led circuit board which has been used to control the timing delay. The led and busser is given to the court for the purpose of practice.

\section{Software Simulation}

The circuit diagram has been stimulated in the Proteus 7.5 version software and program is created in mikroC PRO for pic software and programed .hxe file has been stored to the $16 \mathrm{f} 887$ microcontroller . The circuit diagram represents PIC16F887 microcontroller, switches, led's, resistors.

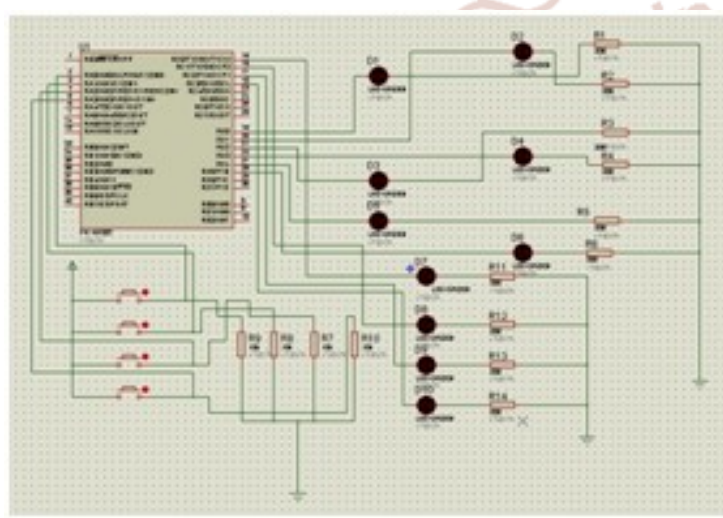

Fig.4 Proteus simulation window for coach-less schema

\section{Diagram of Court}

The diagram of the court explains that the violet colour dot indicate that the led light has been place in court A, B, F, E busser C, D and black dot X indicate that player is standing in centre of the court.

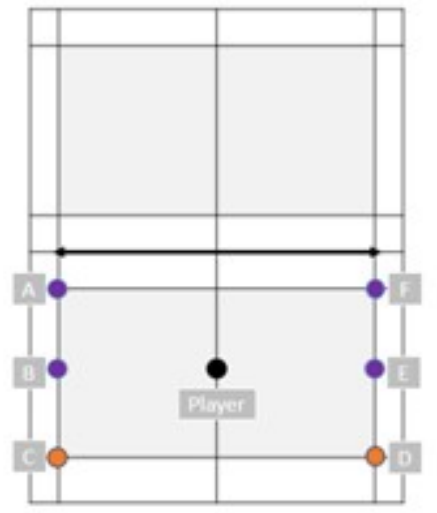

Fig.5 Led and busser nodes

\section{Coding Schema}

The program has been created by the embedded c language. The word embedded system gives the combination of both hardware and software which has been implemented in the proposed project. The programed has been specially created for $16 f 887$ microcontroller by the help of datasheet.

Char value []$=\{\ldots \ldots .$.

Void main()

while(1)

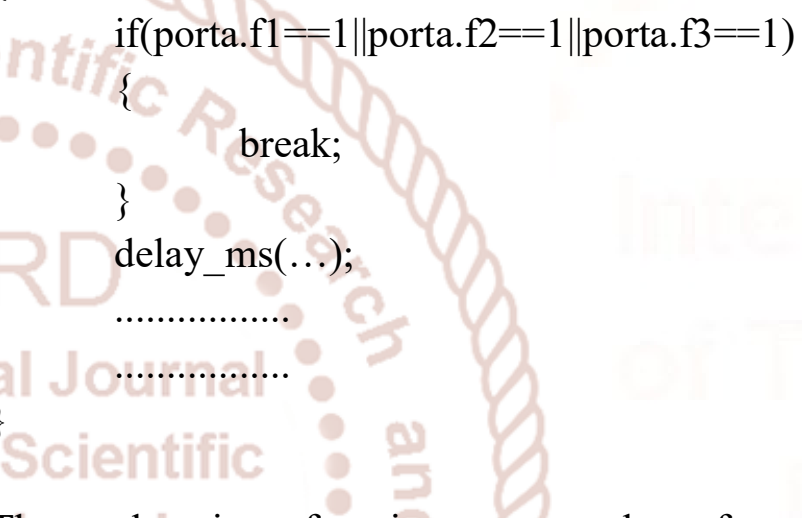

The explanation of project was number of sequence have been given as array value with can be call number of times and it goes to the main function which as a continuous loop of while loop and goes to if statement it will check frequently does any switch is pressed are not if switch is pressed the operation will break and goes to another operation until the program is interrupt by the user.

\section{Cost Analysis}

\begin{tabular}{|l|}
\hline PIC 16F887 Microcontroller \\
Switches \\
Led \\
Busser \\
Resistor \\
Dot matrix board \\
Connecting wires \\
\hline \\
\\
\end{tabular}


International Journal of Trend in Scientific Research and Development (IJTSRD) ISSN: 2456-6470

\section{Advantages}

- Cost efficiency

- Coach-less training

- Coach can tack care of all players

- Easy to use

\section{Result and Discussion}

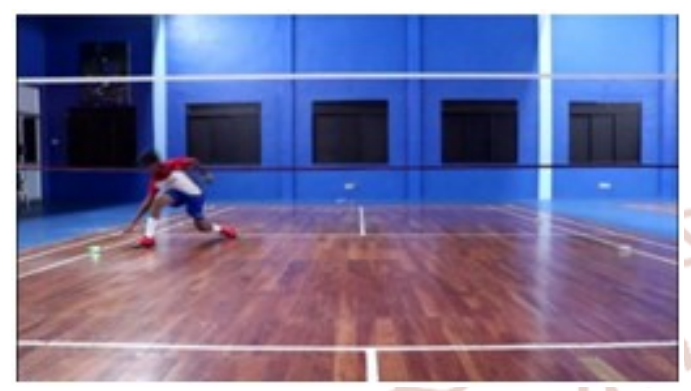

Fig 6 (a) Real time implementation

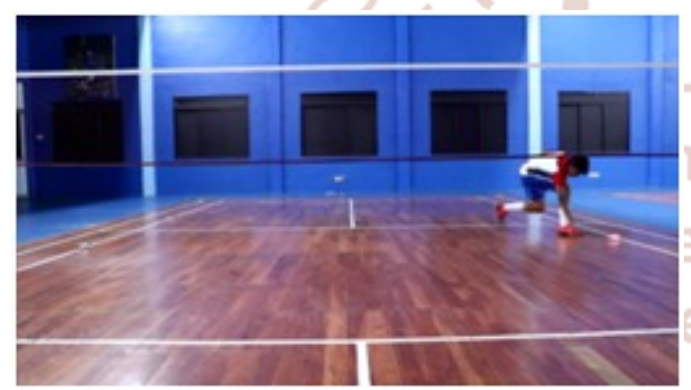

Fig. 6 (b) Real time implementation

The figure 6 shows the real time implementation of coach-less schema. The coach-less schema was designed using proteus software show in figure 4. Further the same circuit was implemented using PIC16F887 and components the prototype was implemented in the figure 7 . This can be used widely for the coaching beginners.

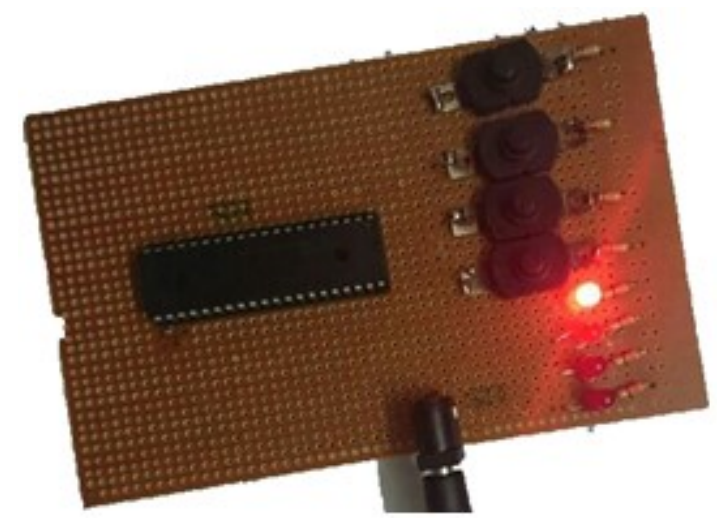

Fig.7 Working prototype-led node

\section{Conclusion}

By using this type of coaching method human work hour will be reduced and lot of money will be saved. The PIC16F887 microcontroller is very less expensive so that anybody can afford it. The prototype was designed successfully and can be processed into a model at very low budget.

\section{REFERENCE}

1. Remya George, Anjaly Cherian.V, “An Intelligent Security System for Violence against Women in Public Places" International Journal of Engineering and Advanced Technology (IJEAT) ISSN: 2249 - 8958, Volume-3, Issue-4, April 2014

2. Nishant Bhardwaj "Design and Development of Suraksha"-A Women Safety Device" International Journal of Information \& Computation Technology. ISSN 0974-2239 Volume 4, Number 8 (2014), pp. 787-792

3. http://www.amritapuri.org/16788/apps.aum

4. https://www.indiegogo.com/projects/safetylinksafety-for-everybody-everywhere

5. John Yin (zy93), Cordelia Lee (cr165) Design with Microcontrollers "An Augmented Pepper-spray with Camera and Emergency Response"

6. http://people.ece.cornell.edu/land/courses/ece4760 /FinalProjects/f2012/zy93_crl65_lt277/Final_Rep ort.pdf

7. https://www.lifefone.com/http://www.livescience. com/43016-bestmedical-alert-systems.html

8. http://www.verizonwireless.com/news/article/201 4/10/6-emergency-wearables-for-women.html

9. www.technologystudent.com/pics/picgen 1.html

10. Design of women safety system using RFID, 8051 microcontroller and GSM based technologya 
International Journal of Trend in Scientific Research and Development (IJTSRD) ISSN: 2456-6470

prototype Shaik Mazhar Hussain1, Shaik Jhani Bhasha

11. K. Balasubramanian and A. Cellatoglu, IEEE, 'Analysis of Remote Control Techniques Employed in Home Automation and Security Systems', 2009.

12. Yanbo Zhao and Zhaohui Ye, IEEE "A Low Cost GSM/GPRS Based Wireless Home Security System", 2010.

13. Wenqi (Wendy) Guo, Student Member, IEEE, William M. Healy, and Mengchu Zhou, Fellow, IEEE, 'ZigBee-Wireless Mesh Networks for Building Automation.

14. Tahmina Begum, Md. Shazzat Hossain, Md. Bashir Uddin and Md. Shaheen Hasan Chowdhury 'Design and Development of Activation and Monitoring of Home Automation system via SMS through Microcontroller' 2009.

15. Xuemei Li, Guangzhou, China and Gang Xu, Li China, 'RFID Based Smart Home Architecture for improving lives'.

16. http://www.simonhuggins.com/courses/cbasics/co urse_notes/session2.html.

17. http://www.cprogrammingreference.com/ShortNot es/ShortNote4.php.

18. http://www.best-microcontroller-

projects.com/temperature-recorder.html

19. http://w3.id.tue.nl/nl/intranet/e_atelier/phidgets/co mponents/

20. http://www.technovelgy.com/ct/Technology-

Article.asp?ArtNum=2

21. http://en.wikipedia.org/wiki/Radio-

frequency_identification

22. http://www.developershome.com/sms/GSMMode

mIntro.asp 